\title{
Solórzano Pereira, Defensor de los Pobres
}

\section{Criollos y peninsulares}

Pertenece a la categoría de hechos incontrovertibles la temprana rivalidad que se manifestó entre criollos y peninsulares en América. Hasta hay que pensar que tal situación surgió ya cuando puede hablarse de criollos en el Nuevo Mundo. Aún más, si no tuvo ocasión de plantearse tempranamente con crudeza se debió, sobre todo, a que el propio hecho de la conquista, con sus urgencias y movimientos, en regiones tan vastas, ejerce el papel de agente diluyente. Eso sĩ, cuando la conquista cede lugar a la organización colonial, la rivalidad se presenta con colores más vivos, y el correr de los siglos (XVII y XVIII) irá poniendo cada vez con mayor evidencia esa situación.

Fundamentalmente, se trata, por un lado, de la actitud de los criollos que se consideran, por el hecho de haber nacido en estas tierras, con tanto o más derecho que los peninsulares para ocupar cargos importantes en las colonias, recibir honores, tierras, etc. En frente, están los peninsulares (con el correspondiente nivel social por supuesto) que consideran al Nuevo Mundo un bien de conquista. Y, aparte de otras franquicias especiales, defienden el derecho que, como pueblo conquistador, asiste a los españoles europeos (o consideran que les asisten).

Desde temprano se palpa también la diferencia que existe entre el Viejo y el Nuevo Mundo. Empezando por la sorprendente naturaleza americana, tan distinta a la que reflejaba el muy gastado mundo europeo. Testimonio de estas elementales diferencias aparecen con extraordinaria abundancia. Desde los primeros cronistas, y en multitud de obras que se ocupan de las tierras descubiertas. Después, las inagotables novedades pasarán a los libros literarios europeos, y no 
será necesario que el escritor haya conocido América: lo importante es que acepte realidades y fantasías en las que caben exageraciones explicables.

Un hombre del siglo XIX, el español Bernardino Fernández de Velasco y Pimentel, llegará a escribir: Un satîrico decía que, en las Indias, solo dos cosas había conformes a las de España, que eran el agua bendita y el vinagre". 1 Comparación en las que nos interesa menos la verdad total que la verdad esencial que descubre.

Como digo, las categorias sociales muestran también diferencias notorias. Y a ellas debemos agregar, por el peso que tienen, las que se vinculan -y tempranamente- al problema del indio. Y, con posterioridad, al problema del negro. Sin embargo, ya hay bastante complejidad en todo aquello que se refiere a los españoles americanos y los españoles europeos. O, si preferimos, entre criollos y peninsulares. Pero aún antes de marcar esta diferencia, sorprendemos la inusitada lucha entre los propios españoles avecindados en América: concretamente, entre los que llevaban un tiempo o años en el continente, y los recién venidos. (Es lo que, en forma tan gráfica, descubren los nombres de baquianos y chapetones).

La serie de niveles no termina aqui. Sin establecer ahora diferencias, es evidente que para muchos españoles peninsulares América significaba no sólo la posibilidad de enriquecimiento, sino también ( $y$ en buena medida como consecuencia de lo anterior) la posibilidad de mejorar su condición social: tĭtulos, cargos... ¿Por qué no? La amplitud del continente (no contemos los riesgos) permitía, por lo menos, esos sueños.

De que tal idea cuajó pronto en la mente de muchos españoles tenemos pruebas en abundancia. Sobre todo, frecuentes sátiras en que se muestra el "delito" de pobretones que usan el Don sin derecho. Quizás el testimonio más serio, por venir de quien viene, es el que encontramos en la Política indiana: ". . . pues no puede ni debe consentirse que todos puedan ser iguales, y cavalleros, en pasando a aquellas tierras. ..".2

Volviendo a los criollos y sus quejas, no sólo en relación a españoles peninsulares, sino también, en ocasiones, extranjeros, los ejemplos son realmente nutridos y variados. Pero, sobre todo, conviene reparar en que el principal derecho que alegan no es otro que su condición de descendientes de los primitivos conquistadores, y las penurias sufridas por éstos. En fin, ya que estas páginas se centran en la figura de Solórzano Pereira, bueno será citar aquí, si no una pieza suya, por lo menos versos de un Romance que perteneció a 
su biblioteca (y que resucitó en nuestro siglo la diligencia de don Antonio Rodríguez-Moñino):
¿En qué razón o ley cabe que los hijos desta tierra y de los que la compraron con sus vidas y haziendas. . . anden como delinquentes por arrabales y breñas, aniquilados y pobres que es campassion y vergüença, y que vengan chapetones de naciones estranjeras y luego tengan officios y echen pajes y libreas. . . 3

\section{Criollos e indios}

No me detendré en el difícil problema del indio, problema sobre el cual se fijan desde temprano, en relación a la conquista, las más dispares interpretaciones. La distancia mayor suele darse entre la posición de determinados defensores del indio (por lo común, defensores piadosos más que justos) y las leyes protectoras, por un lado, frente a la concreta explotación del indio. Con las leyes, o con desconocimiento de las leyes, de parte de los encomenderos.

Por supuesto, debe destacarse la actitud de muchos religiosos que defendieron a los indios de malos tratos y propendieron a una legislación más benigna. Su fuerza se hizo sentir, pero debieron luchar contra la distancia ${ }^{4}$, el aislamiento, malos funcionarios y la rapacidad de los encomenderos. Como la oposición era fuerte, vale la pena citar una vez más los nombres conocidos. Sobre todo, de aquellos que vivieron en América y pudieron palpar más de cerca la condición del indígena: Las Casas, Alonso de Ovalle, Juan de Palafox y Mendoza, Ercilla, Oviedo, El Inca Garcilaso, Juan de Castellanos, Avalos y Figueroa, Solórzano Pereira... (y no pidamos equivalencia en la defensa). 5

Hecha esta elemental aclaración, quiero puntualizar aquí que, dentro de los diferentes niveles que marca la sociedad colonial, el criollo no suele establecer, con respecto al indio, mayores diferencias o aproximaciones que las que caracterizan al europeo. Con otras palabras: se duele, como es de sobra conocido, de lo que considera injusticia para sí, pero no suele acordarse del indio, enemigo o bien 
producto de conquista. El criollo aspira a corregir males que le tocan de cerca, sin pretender por eso modificaciones en otros sectores del complejísimo mundo colonial. 6

Defensa del criollo

Dentro, pues, de la perspectiva que engloban criollos y peninsulares, hay en aquellos siglos abundancia de testimonios, y a ellos me referiré. Sobre todo, con la intención de mostrar que no escasean, como algunos pensaron, los alegatos en favor de los criollos. $\mathrm{Y}$ tanto en América como en España. Procuraré mostrar también algunas particularidades llamativas en ciertas defensas.

Por razones comprensibles, me limitaré a los siglos XVI y XVII. De este modo limitamos adecuadamente el terreno y evitamos la multitud de referencias que aparecen en el siglo XVIII, por otra parte, mejor conocidas.

Además, como he enfocado aspectos de este tema en diversos estudios $^{7}$, dejaré de lado aquellos elogios que no siempre tienen un respaldo efectivo, o que no pasan de una retórica del homenaje. Entendemos, por ejemplo, que pertenecen a este grupo los elogios de Cervantes (Canto de Caliope, en La Galatea, Alcalá, 1585, libro VI) y de Lope de Vega, en diferentes obras (La Filomena, Madrid, 1621; Laurel de Apolo, Madrid, 1630; La Dorotea, Madrid, 1632). ${ }^{8}$

Mayor consistencia tienen, desde España, testimonios como los que vemos, a fines del siglo XVI, en Francisco Sánchez, Alamos Barrientos y Juan López de Velasco. 9

Otra cara aparece en los elogios que, desde América, escriben autores como Juan de Cárdenas y Bernardo de Balbuena. Los dos, desde México. Cárdenas destacaba, en 1591, el "agudo, trascendido y delicado ingenio de los nacidos en Indias"10, y Balbuena cantaba loas a los "hombres eminentes" de México.11 En fin, sin salir de América (o de nombres vinculados a América) puedo citar, en el siglo XVII, al Inca Garcilaso (en su Historia general del Perú, de 1617), al Obispo Piedrahita, santafereño (en su Historia general de las Conquistas del Nuevo Reyno de Granada) y al mexicano Carlos de Sigüenza y Góngora, de tanta fama en su tiempo (en su Libra astronómica, de 1691). Aparte, historias o elogios de órdenes religiosas. ${ }^{12} \mathrm{Y}$, claro, aquellos autores (Diego de León Pinelo y, sobre todo, Solórzano Pereira) de los cuales me ocuparé de manera especial.

Como vemos, la lista precedente, que corresponde por lo común a testimonios escritos en América y que reflejan una actitud de 
defensa de los criollos, no concuerda con algunos juicios modernos en que, por un lado se señala escasez en tales alegatos, $y$, por otro, se repara particularmente en los negativos. 13

\section{Solórzano Pereira y los criollos}

Es tiempo ya de que nos ocupemos del tópico que -ligado a los precedentes señalados- constituye el motivo fundamental de estos párrafos. Me refiero a la defensa de los criollos que hace el famoso jurista Juan de Solórzano Pereira en su Politica Indiana, obra clásica en la materia. 14

No sólo por el carácter detallado que su defensa tiene, sino también porque tal posición tiene en él un franco carácter polémico frente a nombres más o menos ilustres que han desmerecido o niegan francamente virtudes a los españoles americanos.

Antes de entrar en la obra de Solórzano Pereira y en los detalles de su alegato, bueno será mencionar, a manera de anticipo cercano, una situación parecida que pone frente a frente un juicio despectivo del humanista Justo Lipsio y la reacción de Diego de León Pinelo, si bien hay un lapso apreciable entre los dos escritos.

Justo Lipsio, en su obra Lovanium, publicada en Amberes, en 1605, como homenaje a la Universidad de Lovaina, citaba, aparte de ésta, otras universidades de prestigio. Pero también agregaba: "¿Y qué más? ¿Iré al Nuevo Mundo? Allí ciertamente no hay sino barbarie". (No sé si hace falta aclarar que el humanista belga tuvo en España especial acogida y muchos discípulos. Sus obras latinas, algunas traducidas, fueron consideradas como unas de las guias intelectuales de la época).

La respuesta de Diego de León Pinelo llegó un tanto tardíamente, en 1648, cuando era Rector de la Universidad de San Marcos, de Lima. Es, en especial, una apologia de su universidad, juntamente con una loa a la capacidad intelectual de los criollos. ${ }^{15}$

Como digo, me interesa ocuparme de Juan de Solórzano Pereira y su defensa de los criollos. Conviene comenzar diciendo que si su defensa de los indios tiene alternancias (hay verdadera comprensión en algunos aspectos, e incomprensión en otros), tal cosa no ocurre con las macizas consideraciones que le merecen estos "verdaderos españoles". Pero mejor será copiar los párrafos destacados de su alegato:

Declarado ya lo perteneciente al estado y condición de los indios, quiero rematar este libro diciendo algo de los que nacen en las Indias de padres españoles, que alli vul- 
garmente los llaman criollos, y de los que proceden de españoles e indias, que se llaman mestizos, o de españoles y negras, que se dicen mulatos.

En quanto a los primeros, no se puede dudar que sean verdaderos españoles, y como tales hayan de gozar sus derechos, honras y privilegios, y ser juzgados por ellos, supuesto que las Provincias de las Indias son como auctuario de las de España, y accesoriamente unidas e incorporadas en ellas, como expresamente lo tienen declarado muchas Cédulas Reales que de esto tratan, y en términos de derecho común lo enseñan con el exemplo de las colonias de los romanos varios textos y autores a cada paso.

A que se añade que la cosa que se agrega a otra toma y sigue siempre sus calidades, como lo prueba muy a la larga Tyberio Deciano, y que estos hijos de españoles vienen a ser y son oriundos de España, aunque los haya en parte tan remota de ella; y por el consiguiente conforme otras reglas del mismo derecho, no siguen el domicilio, sino el origen natural de sus padres, al qual todas las cosas se suelen reducir y referir de ordinario, reteniendo y conservando la calidad que dél en ellas se deriva según la doctrina de otras leyes y unas elegantes palabras de Casiodoro...

Conviene notarlas, para convencer la ignorancia o mala intención de los que no quieren que los criollos participen del derecho y estimación de españoles, tomando por achaque que degeneran tanto con el cielo y temperamento de aquellas provincias, que pierden quanto bueno les pudo influir la sangre de España, y apenas los quieren juzgar dignos del nombre de racionales, como lo solían hacer los judíos de Jerusalén y Palestina, teniendo y menospreciando por bárbaros a los que nacian o habitaban entre gentiles, como después de otros lo refiere Bernardo Aldrete.

Los que más se estreman en decir y publicar esto son algunos religiosos que pasan de España, pretendiendo escluirles por ello del todo de las prelacías y cargos honrosos de sus Ordenes, o que se han de proveer por alternativa en virtud de ciertos Breves que han impetrado, de que diremos algo en otro lugar. . . 
Si vale algo mi afirmación, puedo testificar de vista y de ciertas oídas de nuestros criollos, que en mi tiempo y en el pasado han sido insignes en armas y letras, $y$, lo que más importa, en lo sólido de virtudes heroycas, egemplares y prudenciales, de que me fuera fácil hacer un copioso catálogo si ya otros no lo huvieran tomado a su cargo, o no temiera agraviar a los que era forzoso pasar en silencio, por no alargar este libro o no ser posible tener noticia de todos. . 16

Yo he trascrito nada más unos pocos párrafos de un extenso capítulo, pero creo haber seleccionado partes esenciales del alegato. Como es normal en Solórzano Pereira, parte éste de la legislación vigente, la analiza, señala casos y opiniones diversas y, entre ellas, no se olvida de fundamentaciones clásicas. Solórzano Pereira es, esencialmente, el jurista, pero asistido, en mucho, por el humanista que revela conocimientos y sensatez.

Como no podía ser menos, Solórzano atiende al problema de los criollos y peninsulares en América. Sobre todo, a las opiniones de peninsulares que menosprecian -por ignorancia o mala intención- a los criollos americanos. Solórzano manifiesta que en el menosprecio hay mucho de interesado, con conexiones a cargos y beneficios (religiosos, civiles) en las colonias.

Una vez más, Solórzano hace hincapié, frente a opiniones mezquinas o enunciadas en lugares muy distantes del Nuevo Mundo, en que su apoyo está, aparte del conocimiento minucioso de la legislacion, en su estudio directo, en sus años de América y en su deseo de justicia, aquí como en multitud de puntos debatidos a lo largo de su copiosa obra. Y no cabe duda de que la culminación del capitulo se alcanza en el párrafo 14 , que es el que comienza: "Si vale algo mi afirmación. .." (pero con éste tendremos oportunidad de establecer, más adelante, un curioso cotejo).

\section{Solórzano Pereira y Suárez de Figueroa}

Quiero detenerme en una breve confrontación entre estos dos hombres, a través de juicios, realmente opuestos, acerca de los criollos. De Solórzano Pereira poco más hay que decir. En cambio, sỉ conviene una mayor noticia sobre Cristóbal Suárez de Figueroa, figura temida en la España de comienzos del siglo XVII.17 Comola relación que procuro establecer no se ha señalado (que yo sepa), justifico así el espacio que a continuación le dedico. 
La fama de bilioso, malhumorado, está indisolublemente unida al nombre de Cristóbal Suárez de Figueroa, quien, por otra parte, tenía también algunas facetas positivas en su personalidad. Desgraciadamente, no es aquí donde destacamos esos aspectos positivos.

Como es fácil adivinar, entre los múltiples temas que desarrolla en su obra mayor, El Passagero, figura el tema de las Indias. Y como el largo discurso que a ellas se refiere está puesto en boca del "Doctor", poco cuesta imaginar que el pensamiento que allî se expone tiene que ver, en forma estrecha, con el pensamiento del autor. Vale decir, de este "Aretino español" que muy pocas cosas encontró dignas de elogio o aprobación.

Suárez de Figueroa comienza ya por decirnos que el nombre de Indias le resulta aborrecible. . .Y lo que sigue no cambia mayormente esta primera impresión. Por el contrario, envuelve a las Indias y los criollos en una continuada serie negativa. Lo más alentador que ofrece (siquiera como contraste) es su conmiseración por los indígenas y sus "miserables vidas". Termina su condenación refiriéndose a los españoles que cruzan el océano, los que -dice-empeoran al tocar América. Veamos, mejor, el texto de Suárez de Figueroa:

[Doctor] Las Indias, para mí, no sé que tiene de malo, que hasta su nombre aborrezco. Todo cuanto viene de allá es muy diferente, y aun opuesto, iba a decir, de lo que en España poseemos y gozamos. Pues los hombres (queden siempre reservados los buenos) iqué redundantes, qué abundosos de palabras, qué estrechos de ánimo, qué inciertos de crédito y fe; cuán rendidos al interés, al ahorro! ¡Qué mal se avienen con los de acá, observando diversas acciones, profesando diferentes costumbres; siempre sospechosos, siempre retirados y montaraces!

¡Pues la presunción es como nueva! Todos, sino ellos, ignoran, todos yerran, todos son inexpertos; fundando la verdadera sabiduria y la más fina agudeza sólo en estar siempre en la malicia, en el engaño y doblez. No he visto hacienda adquirida en aquellas partes lograda bien en las nuestras i Qué deslucidos casi todos, qué misseros, qué faltos de amistad, qué sobrados de odio, qué inútiles, qué despegados, qué malquistos! ¡Notables sabandijas crian los lïmites antárticos y occidentales! Desde que nací aguardo venga de allá algún varón no menos rico que espléndido en quien tenga albergue la virtud, amparo la ciencia, socorro la necesidad ¿Es posible no haya pro- 
ducido en más de un siglo aquella tierra algún sujeto heroico en armas, insigne en letras o singular en cualquier camino? Mas ¿qué puede haber en parte donde tanto triunfan los vicios, donde tanto campea el interés? Todo es destruir, todo es aniquilar las vidas y haciendas de los que tienen entre manos. Tiranos crueles, no blandos mayordomos de los bienes y frutos de aquellos simples, de aquellos inocentes, que sumergidos entre las ondas del perpetuo trabajo despiden las miserables vidas que les quedan, librándose con una de casi infinitas muertes; que por instantes les resulta del incesable sudor, de la insufrible fatiga. Siendo esto así, y que, según se afirma generalmente, los buenos se estragan en pisando aquellos confines ¿de qué sirve para buscar su daño entregarse a los tremendos peligros y a las innumerables molestias de tan larga navegación?.18

Copiado el detallado testimonio, reparemos en una de sus partes:

¿Es posible no haya producido en más de un siglo aquella tierra algún sujeto heroico en armas, insigne en letras o singular en cualquier camino? .

Y, a continuación, desgajemos un párrafo, ya destacado, de Solórzano Pereira:

Si vale algo mi afirmación, puedo testificar de vista y de ciertas oidas de nuestros criollos, que en mi tiempo y en el pasado han sido insignes en armas y letras, $y$, lo que más importa, en lo sólido de virtudes heroycas, egemplares y prudenciales. . .

Solórzano Pereira cita con frecuencia fuentes y noticias que le sirven de apoyo. De la misma manera, cuando rebate, no oculta los nombres de aquellos a los cuales se opone. Concretamente, en su capítulo sobre los criollos rebate, fuera de un anónimo obispo de México, a Fray Juan de la Puente (que considera que las tierras de América son más propicias para hierbas y metales que para hombres de provecho), y al $P$. José de Acosta (que echa la culpa ia los indios! del empeoramiento de los españoles que cruzan el mar).

En cambio, no menciona para nada a Suárez de Figueroa y $E l$ Passagero. Más allá de vocablos y coincidencias casuales (que la identidad del tema suele determinar) creo que el cotejo de los textos muestra algo más que una vaga semejanza. Da la impresión de que 
Solórzano Pereira está respondiendo, con claridad, al denuesto de Suárez de Figueroa.

¿Por qué no menciona Solórzano al autor de El Passagero? Quizás vivía cuando elaboró su primera versión (la latina), ya que si no se conoce exactamente el año de la muerte de Suárez de Figueroa se cree que ocurrió en 1639. (Por otra parte, no conozco el texto latino de Solórzano) Con esta sospecha, cuesta poco imaginar que Solórzano no quería polémicas con el irascible Suárez de Figueroa. Aunque pueda aducirse que la respuesta es bastante directa, verdad también es que falta el nombre propio. No sé. Lo concreto es que, por un lado, los dos textos dan la impresión de un breve y áspero diálogo. Y, por otro, que Solórzano diluye su respuesta aludiendo, más que a una cita libresca y española, a las cosas que él ha visto de cerca en sus años americanos. . Pero -insisto- a mi modo de ver hay una estrecha relación entre la cáustica condena de Suárez de Figueroa (expuesta en una obra que tuvo bastante difusión) y la serena defensa ensayada por Solórzano Pereira.

\section{Conclusión}

Recuerdo que en una Introducción de Ricardo Levene, publicada hace ya muchos años, nuestro conocido historiador recalcaba que Solórzano Pereira "figura entre los pocos escritores que defendieron con amor a los criollos, exaltaron sus virtudes y capacidad y proclamaron la necesidad de reconocerles iguales derechos que a los españoles". ${ }^{19}$ La cita fue recogida años después, con muestras de aprobación, por el distinguido investigador y especialista en Derecho indiano, don José Maria Ots Capdequî. 20

A través de los testimonios recogidos en las páginas precedentes, de otros que pueden sumarse 21 , y de nuevos nombres que puedo agregar ahora, reconocemos, en primer lugar, que no fueron pocos los que, a ambos lados del mar, defendieron a los criollos. Que, por el contrario, ya a partir del siglo de la conquista y con acumulada proporción en los siglos XVII y XVIII hay una verdadera y encadenada polémica en la que, por una parte se desmerece a los criollos (y aquí entran tanto españoles peninsulares como europeos en general). $Y$, por otra, se los defiende con diversidad de razones. En este bando figuran tanto españoles peninsulares como los propios criollos destacados que, desde América, procuran hacer valer sus méritos, no inferiores, piensan, a los que pueden hacer valer los españoles europeos que los desmerecen.

En una cosa conviene dar la razón a Ricardo Levene: en pocos encontró la defensa de los criollos tantos argumentos jurïdicos y hu- 
manistas como los que manejó Solórzano Pereira. Y éste puede ser también lugar apropiado para destacar que nuestro autor, si bien alcanza su culminación como jurista, tuvo otras facetas dignas de recuerdo (como autor de emblemas, poeta lírico, bibliófilo, etc.). 22

Esta acumulada defensa de los criollos crecerá, si cabe, a lo largo del siglo XVIII y, entre otras cosas, servirá de firme sostén a los anticipos revolucionarios de fines del siglo $23 \mathrm{y}$, no menos, a las luchas de Independencia de comienzos del siglo XIX. Después de todo, no hay que olvidar que estas luchas tuvieron como sostén exclusivo (o casi exclusivo) a los españoles americanos o criollos que, en varios lugares, se proclamaban simplemente "americanos".

Volviendo a la figura de Solórzano Pereira es de rigor reiterar una vez más que fue él uno de los que mejor luchó por el buen nombre de los criollos (no en el mismo nivel, aunque tiene igualmente sus aportes, en el caso de los mestizos e indios). ${ }^{24}$ En conjunto, es difícil encontrar otro nombre equivalente cuando se enfoca el complejo cuerpo jurídico conocido como "Derecho Indiano". Disciplina que, no por casualidad, nos acerca al título mayor de su bibliografía. La posteridad y, sobre todo, estudiosos de nuestro siglo han rendido a Solórzano Pereira el homenaje que merece. Recuerdo que Ricardo Levene proclamaba a Solórzano "el creador de la ciencia del Derecho Indiano".25 Y en otro lugar decía que su Politica Indiana era la obra de más trascendencia sobre el tema escrita en los tres siglos de dominación española en América. 26 "Insigne jurista" lo llamó don Antonio Rodrìguez- Moñino;27 "tratadista eminente", el investigador del tema, don José María Ots Capdequí. 28 En fin, el estudioso italiano Antonello Gerbi, a quien debemos un libro capital sobre "La disputa del Nuevo Mundo", lo llamó "el honrado Solórzano". 29 Por supuesto, todos estos elogios tienen en cuenta, no un motivo particular como el que hemos perseguido, sino un caudaloso cuerpo de doctrina. Lo que importa, para concluir, es que su defensa de los criollos sería, para siempre, uno de sus timbres de honor y uno de los principales respaldos en la supervivencia de su nombre.

Universidad de Tucumán, Argentina

EMILIO CARILLA

University of California, River Side

\section{NOTAS}

1. B. Fernández de Velasco y Pimentel (1783-1851), Deleite de la discreción y fácil escuela de la agudeza, ed. de Buenos Aires, 1947, pág. 163.

2. Solórzano Pereira, Política Indiana ( $1^{\text {a }}$ ed., Madrid, 1647), Libro II, cap. III. En todas las citas de esta obra sigo el texto publicado en nuestro siglo 
por el erudito José Marìa Ots Capdequĩ, con las ilustraciones de Francisco Ramiro de Valenzuela (editor del siglo XVIII). Edición en 4 tomos, Madrid, s. a., Compañĩa Ibero-Americana de Publicaciones.

3. Romance peruano anónimo, encontrado en la Biblioteca de Solórzano Pereira y publicado por don Antonio Rodríguez-Moñino. (Ver Manuscritos literarios peruanos en la Biblioteca de Solórzano Pereira, en la revista Caravelle, de Toulouse, $1966, \mathrm{n}^{\circ} 7$, págs. 116-117).

4. Una noticia y un comentario vinculados al tema. En 1624 Solórzano Pereira era Oidor de la Audiencia de Lima. Fue propuesto para el cargo de Fiscal del Consejo de Indias, pero su designación fue pospuesta "por hallarse a considerable distancia de la Corte". (Cf. J.M. Ots Capdequǐ, Prólogo a Solórzano Pereira, Política Indiana. I, ed. citada, pág. II). Y -de otra época y con otro tonoun dicho del inquieto Fray Servando Teresa de Mier:

"Desde la conquista es un apotegma en la boca de los mandarines de América: Dios está muy alto, el Rey en Madrid, y yo aquĩ. .." (Memorias, ed. de Madrid, s.a., Ed. América, pág. 170).

5. Y agregamos en el siglo XVIII: Orsúa y Vela, Llano Zapata, Ulloa, P. Cardiel Maziel, P. Iturri, Clavigero, y muchos más. . .

6. Creo que Ots Capdequi da una visión bastante exacta de esa sociedad de españoles, mestizos, indios y negros. Y en el valor de su sintesis importa también su condición de español.

'La masa colonizadora de españoles que no logró sobrepasar las capas sociales inferiores -pequeños cultivadores de la tierra, menestrales y artesanos de las ciudades- vivieron económicamente con el esfuerzo de su propio trabajo, agrupados en sus corporaciones gremiales los especializados en distintos oficios que estuvieron radicados en poblaciones relativamente importantes, y a la sombra protectora, en el orden político y administrativo, de las viejas instituciones municipales de Castilla trasplantadas a estos territorios.

Se entrecruzaron con estos grupos sociales de españoles los mestizos y los criollos. No constituyeron éstos una clase social propiamente dicha ni en el orden jurídico ni en el orden económico. El derecho indiano los situó en un plano de igualdad con los propios españoles peninsulares aquĩ radicados. Pero la realidad social fue muy otra. Con reiteración fueron apartados de los altos puestos de la vida política y administrativa de las ciudades coloniales, a pesar de las nobles advertencias de algunos tratadistas eminentes, como Juan de Solórzano.

Ya en una esfera servil o intermedia entre la servidumbre y la libertad, completan el cuadro de los grupos sociales del período colonial, los negros importados de tierras africanas y los indios aborigenes de las distintas comarcas conquistadas.

Los primeros vivieron en una situación de esclavitud, salvo en aquellos casos en que consiguieron la libertad por la manumisión. La 
condición jurídica, económica y social de los segundos, presenta una complejidad mayor, y por su interés histórico merece ser expuesta con una mayor amplitud". (J.M. Ots Capdequï, El estado español en las Indias, México, 1941, pág. 26).

7. Ver mis estudios Americanismo literario (Santiago de Chile, 1963), Raices del americanismo literario (Bogotá, 1968) e Hispanoamérica y su expresión literaria (Buenos Aires, 1969).

8. A su vez, Francisco Fernández de Córdoba elogia al Capitán Olivares y Butrón y a otros ingenios del Perú en los preliminares de la obra de Olivares Concepcion de María Puríssima (Lima, 1631). Y el punto de referencia del elogio no es otro que el poema de Belardo a la "indiana" Amarilis. (Cit. por Luis Jaimes Cisneros, Amarilis: otra posible huella, en la revista Mar del Sur, de Lima, 1953, No 26, pág. 74).

9. Ver Francisco Sánchez, De multum nobili et prima, universali scientia quod nihil scitur (1581). Cf., traducción de Menéndez y Pelayo con el título Que nada se sabe (ed. de Buenos Aires, 1944, pág. 132). Baltasar Alamos y Barrientos (atrib.), Discurso a Felipe III, de 1598 (cit. por Rufino J. Cuervo, El castellano en América, ed. de Buenos Aires, 1947, págs. 125-126). Juan López de Velasco, Geografía y descripción universal de las Indias (de fines del siglo XVI. Ver ed. de Madrid, 1894, págs. 37-38).

10. Cf. Dr. Juan de Cárdenas, Problemas y secretos maravillosos de las Indias, México, 1591. Ver edición facsimilar, de Madrid, 1945, fols. 176-182.

11. Cf. Bernardo de Balbuena, Grandeza Mexicana, México, 1604, pág. 34. Ver, también, Siglo de Oro en las selvas de Erifile, Madrid, 1608, fol. $101 \mathrm{v}$.

12. Ver, tambian, los nombres que señala Antonello Gerbi. Particularmente, obras de religiosos que destacan, en relación a diversas órdenes, a los nacidos en América: el P. Oliva (jesuittas), el P. Antonio de la Calancha (agustinos), Fray. Juan de Meléndez (dominicos), el P. Francisco A. de Montalvo. . (Ver A. Gerbi, La disputa del Nuevo Mundo, trad. de Antonio Alatorre, México, 1960).

13. Ricardo Levene, Introducción a la historia del derecho indiano (Buenos Aires, 1924); José María Ots Capdequí, Instituciones sociales de la América española en el período colonial (La Plata, 1934). Esto sea dicho con el respeto que me merece la obra realizada por Levene y Ots Capdequí.

14. Juan de Solórzano Pereira (1575-1655) nació en Madrid. Fue estudiante temprano en Salamanca y en 1599 obtuvo su título de Licenciado en Leyes. Fue allí profesor durante doce años, en las cátedras de Prima, Digesto Viejo y Vísperas de Leyes. En 1607 se recibió de Doctor. Recomendado por el Conde Lemos fue nombrado en 1609 Oidor de la Real Audiencia de Lima. En la ciudad virreinal se casó con la criolla Clara Paniagua de Loaysa y Trexo. En Lima comenzó a reunir material vinculado con el derecho indiano. Por lo pronto, en 1622 terminó el Libro primero de la Recopilación (antecedente de sus obras mayores).

En 1626 regresó a España y continuó brillantemente su carrera. Asĩ, en 1627 fue designado Fiscal del Consejo de Indias y, dos años después, Miembro honorario del Consejo de Castilla. 
En años posteriores trabajó activamente en las obras jurǐdicas que le dieron fama. El rey Felipe IV lo nombró en 1640 Caballero de la Orden de Santiago. Se jubiló en 1644 y murió en Madrid el 26 de septiembre de 1655, a los 80 años de edad. Obras principales: Libro primero de la Recopilación. . .[1622] (publicado en Buenos Aires, 1945, dos tomos); Disputationen de Indiarum iure. . . (primera parte, Madrid, 1629); De Indiarum iure... (segunda parte, Madrid, 1639); Política Indiana (Madrid, 1647. En parte traducción, y en parte, no, de la obra latina); Emblemas (Madrid, 1653). . .

Su obra más difundida es, con gran ventaja, la Política Indiana (ver, también ediciones de Amberes, 1703; de Madrid, 1776, con las notas del Licenciado Francisco Ramiro de Valenzuela; reproducida en nuestro siglo, con prólogo de J.M. Ots Capdequĭ, 4 tomos, Madrid, s.a., Compañia Ibero-Americana de Publicaciones). Estudios: José Torre Revello, Ensayo biográfico sobre Juan de Solórzano Pereira (Buenos Aires, 1929); José Marĩa Ots Capdequǐ, prólogo a Solórzano Pereira, Política Indiana (I, ed. de Madrid, s.a., págs. I-V); Ricardo Levene, prólogo a Solórzano Pereira, Libro primero de la Recopilación. . . (I, Buenos Aires, 1945, págs. XI-XXXIII); Ricardo Levene, En el Tercer Centenario de la "Política Indiana" (en La Prensa, de Buenos Aires, 12 de octubre de 1947); Antonio Rodríguez-Moñino, Manuscritos literarios peruanos en la biblioteca de Solórzano Pereira (en la revista Caravelle, de Toulouse, 1966, $\mathrm{n}^{\circ} 7$, págs. 93-125).

15. Cf. Antonello Gerbi, Diego de León Pinelo contra Justo Lipsio: Una de las primeras polémicas sobre el Nuevo Mundo (en la revista Fénix, de Lima, nos. 2-3, 1945-1946). Conviene agregar que Diego de León Pinelo nació en Córdoba del Tucumán. Fue hermano del famoso polígrafo Antonio de León Pinelo. XXX.

16. Ver Solórzano Pereira, Política Indiana, ed. citada, Libro II, cap.

17. Si bien la producción del Doctor Cristóbal Suárez de Figueroa (1571- ¿1639?) abarca diversos géneros y títulos (poesía épica, novela pastoril, obras eruditas, traducciones) el principal soporte de su nombre sigue siendo $E l$ Passagero (1 ${ }^{\mathrm{a}}$ ed., Madrid, 1617), diálogo "de camino" entre cuatro personajes, uno de los cuales -El Doctor- descubre más directamente el pensamiento del autor. Los puntos debatidos son abundantes, si bien predominan los literarios, los políticos y los sociales. Entre los literarios, predominan las alusiones a escritores de la época, alusiones encubiertas más que directas. Las opiniones defendidas descubren la tendencia clasicista del autor, en pugna con manifestaciones barrocas entonces en boga. (Cf., J.P.W. Crawford, Vida y obras de Cristóbal Suárez de Figueroa, trad. de Narciso Alonso Cortés, Valladolid, 1911; Francisco Rodrĭguez Marĭn, prólogo a Suárez de Figueroa, El Passagero, ed. de Madrid, 1913; Juaquĭn de Entrambasaguas, Una guerra literaria del Siglo de Oro. Lope de Vega y los preceptistas aristotélicos, Madrid, 1932).

18. Cristóbal Suárez de Figueroa, El Passagero, alivio IV. Ver ed. de Madrid, 1945, págs. 289-291. 
19. Ver Ricardo Levene, Introducción a la historia del derecho indiano, ed. de Buenos Aires, 1924.

20. Ver José Marìa Ots Capdequì, Instituciones sociales de la América española en el periodo colonial, La Plata, 1934, pág. 44.

21. Cf. mis estudios Raices del americanismo literario (Bogotá, 1968) e Hispanoamérica y su expresión literaria (Buenos Aires, 1969). Aparte, el importante libro de Antonello Gerbi, La disputa del Nuevo Mundo (trad. de Antonio Alatorre, México, 1960).

22. Ver Antonio Rodriguez-Moñino, Manuscritos literarios peruanos en la biblioteca de Solórzano Pereira, ed. citada, págs. 93-99.

23. Salvador de Madariaga destacó, entre otras cosas, la fuerte influencia de Solórzano en Victoriano Villava, a fines del siglo XVIII. Villava fue Protector de naturales y Fiscal de la Audiencia de Charcas. En sus escritos recomendó cambios radicales dentro del sistema político y económico americano. (Ver S. de Madariaga, Cuadro histórico de las Indias, Buenos Aires, 1945, págs. 672-673).

La obra del jesuita italiano Filippo Salvatore Gilij (uno de los expulsados) revela igualmente el aprovechamiento de las ideas de Solórzano, a fines del siglo XVIII. (Ver A, Gerbi, La disputa del Nuevo Mundo, ed. citada, pág. 205).

24. Con respecto a los mestizos escribió Solórzano: "Los mestizos es la mejor mezcla que hay en Indias. .." (Política Indiana, Libro II, cap. XXX).

Ver también, entre los defensores del mestizaje, al Inca Garcilaso, Ruy Díaz de Guzmán, Antonio de Ulloa, Azara. . .

25. Cf. Ricardo Levene, Prólogo a Solórzano Pereira, Libro primero de la Recopilación. .. I, ed. de Buenos Aires, 1945, pág. XIII. citada.

26. Ricardo Levene, En el Tercer Centenario de la "Politica Indiana", ed.

27. Antonio Rodriguez-Moñino, Manuscritos literarios peruanos en la biblioteca de Solórzano Pereira, ed. citada, pág. 93. pág. 26.

28. José Marĭa Ots Capdequí, El estado español en las Indias, ed. citada,

29. Antonello Gerbi, La disputa del Nuevo Mundo, ed. citada, pág. 165. 
